\title{
Performance evaluation of a pull type two rows granular urea applicator
}

\author{
M. Alam*, T. R. Sarker and T. A. Orin \\ Dept. of Farm Power and Machinery, Bangladesh Agricultural University, Mymensingh-2202, Bangladesh, *E-mail: \\ murshedalambau@yahoo.com
}

\begin{abstract}
Deep placement of super granular urea is very laborious and time consuming work for manually operation. To overcome the human stress and drudgery to place the super granular urea, a low cost manually operated pull type 2rows granular urea applicator (GUA) was designed and developed in the department of Farm Power and Machinery, Bangladesh Agricultural University, Mymensingh. The performance of machine was done in agronomy field of Bangladesh Agricultural University. The effective field capacity was $0.11 \mathrm{ha} / \mathrm{hr}$ at a forward speed of $1.78 \mathrm{~km} / \mathrm{hr}$ and $78.89 \%$ field efficiency of developed granular urea applicator. The average distance between two dropped granular urea (GU) from left hopper \& right hopper were $40.64 \mathrm{~cm}$ and $40.89 \mathrm{~cm}$ respectively. The average missing rate of $\mathrm{GU}$ dropped during field operation was $1.65 \%$ for granular urea size of $2.83 \mathrm{gm}$. The depth of granular urea placement was $7-10 \mathrm{~cm}$ in puddle field. The pulling force and draft of the developed applicator were varied between $5-11 \mathrm{~kg}$ and 3-6.62 kg respectively. The draft power was $0.027 \mathrm{~kW}$ for $55.38 \mathrm{~N}$ pulling force at $1.78 \mathrm{~km} / \mathrm{hr}$ speed. The application rate of the GUA was $170 \mathrm{~kg} / \mathrm{ha}$. The results of field and laboratory test of the developed applicator were better in comparison to other models of GUA. The operational cost of the applicator is $390 \mathrm{Tk} / \mathrm{ha}$ which is lower than $22.16 \%$ of BARI made push type GUA and $53 \%$ lower than the manually placement of GU. Average grain yield was highest (5234 kg/ha) when granular urea were applied by the developed applicator and followed by GU applied by BRRI made push type GUA (5213 kg/ha) and GU applied by manually (5209 kg/ha). The highest straw yield (6787 kg/ha) was obtained when GU applied by manually. However the differences of grain yields and straw yields were not significantly difference for applying GU by the applicators and manually operation. The manufacturing cost of the applicator is only Tk.6000. The weight and the drawbar power of the applicator were $15 \mathrm{~kg}$ and $0.03 \mathrm{~kW}$ respectively. Therefore one person (man or women) is enough to pull the machine. Overall performance of the applicator was found quite satisfactory. For this reason, the applicator may be introduced in Bangladesh to apply super granular urea.
\end{abstract}

Keyword: Granular urea, Applicator, Pull Type and Performance

\section{Introduction}

The expansion of modern agricultural practice together with intensified cultivation has led to a high demand for fertilizers to match the increasing demand for food. Chemical fertilizer is one of the main inputs which are required for increasing crop production, (NAP, 2009). Nitrogen is the nutrient that is required in largest quantity and urea is the principal nitrogenous fertilizer for rice production. The fine ureas reduce the effectiveness of fertilizer and may loss up to $70 \%$. The losses occur in following ways; i) some of the fertilizers convert into gaseous form and mix with air, ii) some of them are dissolved with rain or irrigation water and runoff to surrounding canal and river from the applied field, and iii) some of these go beyond the root zone of the rice plants. The problems of prilled urea can be minimized by applying super granular urea at a depth of 7-10 cm in rice filed and this will increase $20-25 \%$ rice production. Granular urea is placed at 7-10 cm deep at the center of 4 consecutive hills of 2 adjacent rows at 20-25 days after transplanting (Bhuiyan, et. al., 1998). IFDC (2007) stated that about 35\% urea is loss in case of split application of urea. On the other hand, only $4 \%$ urea is loss in case of urea supper granular (USG). However, there are few machines for applying granular urea in Bangladesh whose performance is not up to the mark. Usually farmers are applying USG by hand and it is laborious \& time consuming. It takes 200-300 man-hr to apply in 1 hectare land. It also creates back pain, and diseases in legs and fingers of the operator. On the other hand, it is not possible to place a granular urea in an accurate depth and distance by hand. Different organizations (BRRI, BARI, BAU, BMTF, BEVCO etc) designed and developed various GUA but those are all push types. It is clear that push type granular urea applicator (GUA) will require more force to push and field capacity will be low. Ajoy and Fazlu et. al., (2012) designed and developed a pull type GUA but performance was not done in field level. It is necessary to perform intensive laboratory and field experiments to find the performance of machine before introducing it in the field. Therefore the main objective of the research was to study the performance of the machine and compare that with other existing methods of granule urea placement. 


\section{Methodology}

Ajoy and Fazlu (2012) designed and developed a pull type two rows granular urea applicator. However, they did not determine the performance of the machine in the field experiment. Therefore, a research was under taken to find the performance of the applicator at the agronomy field of BAU. The specification of the applicator is shown in Table 1.

Table 1. Specification of developed granular urea applicator

\begin{tabular}{|c|c|}
\hline Particulars & Description \\
\hline Name: & Pull type granular urea applicator \\
\hline Source of power: & Manual \\
\hline Source of power for driving metering mechanism: & Driving wheel \\
\hline 1. Weight of the machine, $\mathrm{kg}$ & 15 \\
\hline $\begin{array}{l}\text { 2. Dimension of the machine: } \\
\text { length, } \mathrm{cm} \\
\text { width, } \mathrm{cm} \\
\text { height (over ground), } \mathrm{cm}\end{array}$ & $\begin{array}{r}155 \\
80 \\
20\end{array}$ \\
\hline 3. No. of operator: & One \\
\hline $\begin{array}{l}\text { 4. Traveling speed, } \\
\text { In dry lad, } \mathrm{km} / \mathrm{hr} \\
\text { In puddle land, } \mathrm{km} / \mathrm{hr}\end{array}$ & $\begin{array}{l}3.42 \\
1.78\end{array}$ \\
\hline 5. Metering system; & Four cups rotate with shaft \\
\hline $\begin{array}{l}\text { 6. Capacity of each hopper, } \mathrm{kg} \\
\text { material }\end{array}$ & $\begin{array}{l}2 \mathrm{~kg} \\
\text { M.S sheet }\end{array}$ \\
\hline 7. GU dropping mechanism: & Gravitational force \\
\hline 8. $\quad$ Furrow opener; & M.S flat bar, $3.81 \mathrm{~cm} \times 3.81 \mathrm{~cm}, 9 \mathrm{~cm}$ long \\
\hline 9. Covering device: & M.S angle bar, $5.08 \mathrm{~cm} \times 5.08 \mathrm{~cm}, 9 \mathrm{~cm}$ long \\
\hline 10. Furrow opener and closer attachment: & M.S rod \\
\hline 11. Ground wheel: diameter & $50 \mathrm{~cm}$ \\
\hline $\begin{array}{c}\text { 12. Handle: material } \\
\text { height }\end{array}$ & $\begin{array}{l}\text { M.S rod covering with PVC pipe } \\
\text { Changeable }\end{array}$ \\
\hline 13. Recommended traveling speed: & $1.7-3.5 \mathrm{~km} / \mathrm{hr}$ \\
\hline 14. Application rate, $\mathrm{kg} / \mathrm{ha}$ & 170 \\
\hline 15. Pulling force, $\mathrm{kg}$ & $5-11$ \\
\hline 16. Draft, kg & $3-6.62$ \\
\hline 17. Required power (maxm), kW & 27.38 \\
\hline 18. Field efficiency, $\%$ & 77.25 \\
\hline 19. Manufacturing cost, Tk & $6500 /-$ \\
\hline 20. GU placement cost, Tk/ha & $390 /-$ \\
\hline
\end{tabular}

Weight of the machine is important, because less weight is easy to carry and maneuver in the field. The weight of the applicator was taken by spring balance and data was recorded. Weight of single GU is very important for application. Thus the weight of each $30 \mathrm{GUs}$ was measured in the laboratory. Weight of GU was measured by a digital balance and the size of each $30 \mathrm{GU}$ was measured by a slide caliper.

\section{Determination the capacity of the applicator}

The capacity of the applicator was considered as the weight of dropped granular urea per unit time or area. To determine the capacity of the applicator, the machine was placed over two benches keeping free both the wheels. Two polythene bags were fixed with the two discharge tubes of metering devices. One person rotates the wheel for 25 times as equivalent to the normal walking speed in the puddle field (1.78 $\mathrm{km} / \mathrm{hr}$ ). It may be mentioned here that theoretically 25 revolutions of the wheel will drop $100 \mathrm{GU}$ in each bag. Since, there are 4 cups in the metering device. The time require for 25 revolutions of wheel was recorded by a stop watch. Uniform speed of wheel rotation was maintained during the experiment. Then, the weight of granular urea which was collected in each bag was measured by an electric balance. The capacity of GUA was estimated by following equation:

Capacity of the applicator $=\frac{\mathrm{W}_{1}}{\mathrm{~T}} \mathrm{~kg} / \mathrm{hr}, \mathrm{C}_{\alpha}=\frac{\mathrm{W}_{1}^{\top} \times 10000}{\pi \mathrm{DW}}$

where,

$\mathrm{C}_{\mathrm{a}}=$ Capacity of the applicator in $\mathrm{kg} / \mathrm{ha}, \mathrm{W}=$ Width of the applicator in $\mathrm{m}, \mathrm{D}=$ diameter of the wheel in $\mathrm{m}, \mathrm{W}_{1}=$ weight of the dropped granular urea in both hoppers in $\mathrm{kg}$, and $\mathrm{T}=$ time require for 25 revolutions of wheel, $\mathrm{hr}$. 


\section{Determination of missing rate}

The hoppers of the applicator were filled with granular urea and the metering device was rotated for one minute by turning the wheels. Number of turn was counted and time was recorded by a stop watch. Dropping GU was counted and recorded. This experiment was done for 5 times. Then the missing percentage of $\mathrm{GU}$ was calculated using the following equation:

Over falling or missing $\%=\left[\frac{(\mathrm{N} \times \mathrm{Y})-\mathrm{NG}}{(\mathrm{N} \times \mathrm{Y})} \times 100\right]$

where,

$\mathrm{N}=$ Number of turn of wheel per minute, $\mathrm{Y}=$ No. of cups in the metering device, and NG = Total number of granular urea fallen per minute

\section{Distribution pattern of GU drop on dry land}

In order to simulate field condition, the applicator was run over dry land at normal walking speed. A measuring tape was used to measure the distance between GUs and a stopwatch was used to record the time. The space between the granules urea were measured and recorded. The descriptive statistics (mean, media, mode, max, min etc.) of the data were analyzed by excel program. The applicator was operated in the puddle land in the laboratory of Farm Power \& Machinery to observe the function of metering device, furrow opener and closer. The traveling time and lap length were recorded during the operation to find the speed and field capacity of the applicator in puddle land.

\section{Draft measurement of the applicator}

The force requirement to pull the GUA was determined in the laboratory by fixing a spring balance. It was fixed in the handle and pulled the applicator. The operation was recorded by a digital camera (5xZoom, 14.1 mega pixel, Sony) in video mode. The video file was played by KMplayer software. Various images of spring balance in different times of operation were captured by playing the video file by KMplayer. From the images of spring balance, pulling forces were recorded. The flow chart to find the force required to pull the machine is shown in Fig.1.

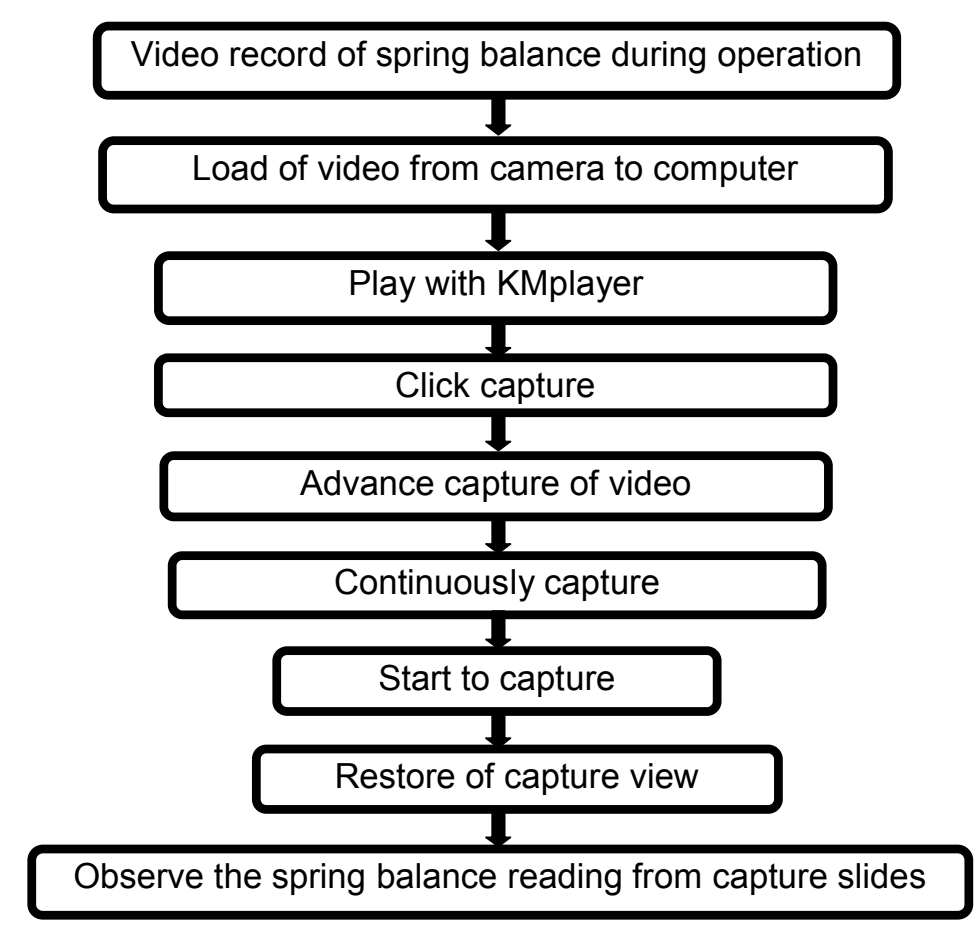

Fig.1. Flow diagram of collection data from video file 
Draft may be defined as the horizontal component of the pull parallel to the line of motion. Mathematically, Draft, $D=P \cos \alpha \cos \beta$

where,

$P=$ Pulling force, $\alpha=$ Angle between pull $\&$ ground, and $\beta=$ Angle of pull with the line of motion.

The height and horizontal length of pulling were measured by a tape for calculating the pulling angle, Fig. 2. By measuring the height and width of the triangle, the pulling angle was determined using the following formula.

Pulling angle, $\alpha=\tan ^{-1} \frac{\text { Height of triangle }}{\text { Width of triangle }}$
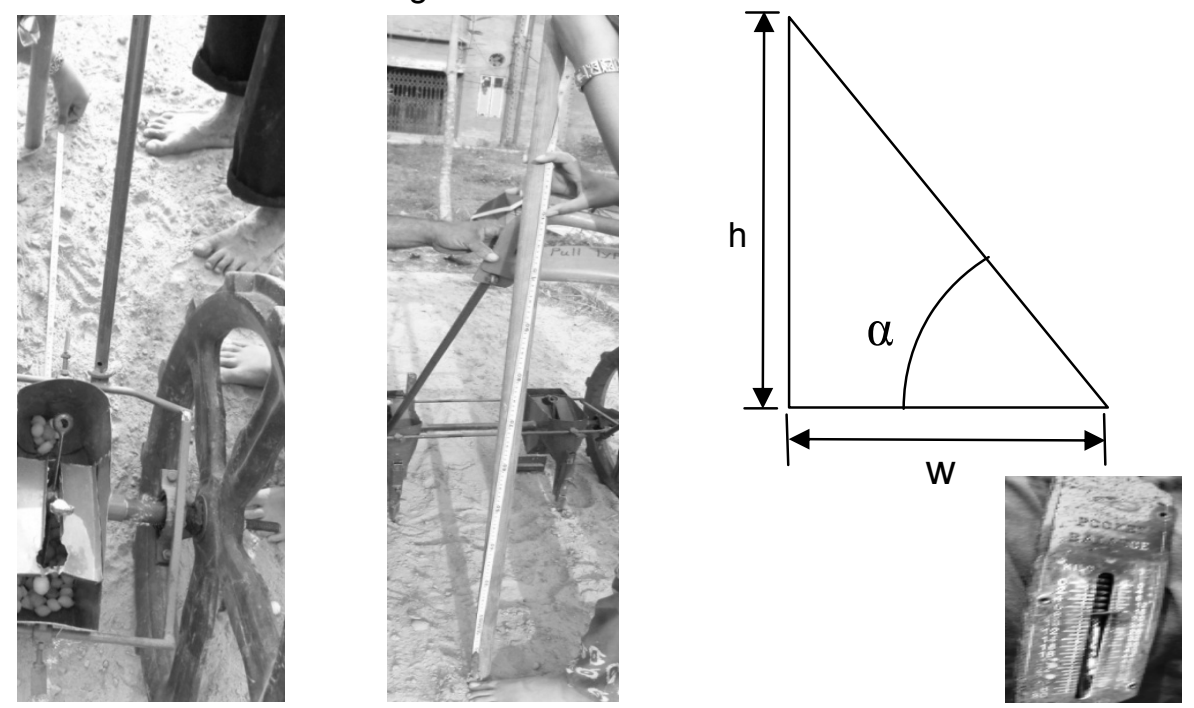

Fig. 2. Different views for measuring height $\&$ width of pulling angle

\section{Field test of the applicator}

Field test was done at BAU Farm. It was conducted to collect data to determine the overall performance of the applicator, spacing between two granular urea, depth of GU placement, operating speed, field capacity, application rate, and cost per unit area and time.

\section{Spacing between GU to GU}

The distance between two GUs was measured in long run operation in the field to observe the performance of GU drop. Field was prepared by a power tiller with three operations. Then, the applicator was operated in dry land to obtain granular urea to granular urea distance. For this purpose, GUA was operated without furrow closer to record the distance between GU to GU and the distances were measured by a tape. The operation of applicator and measurement of distance between GU to GU are shown in Fig. 3.
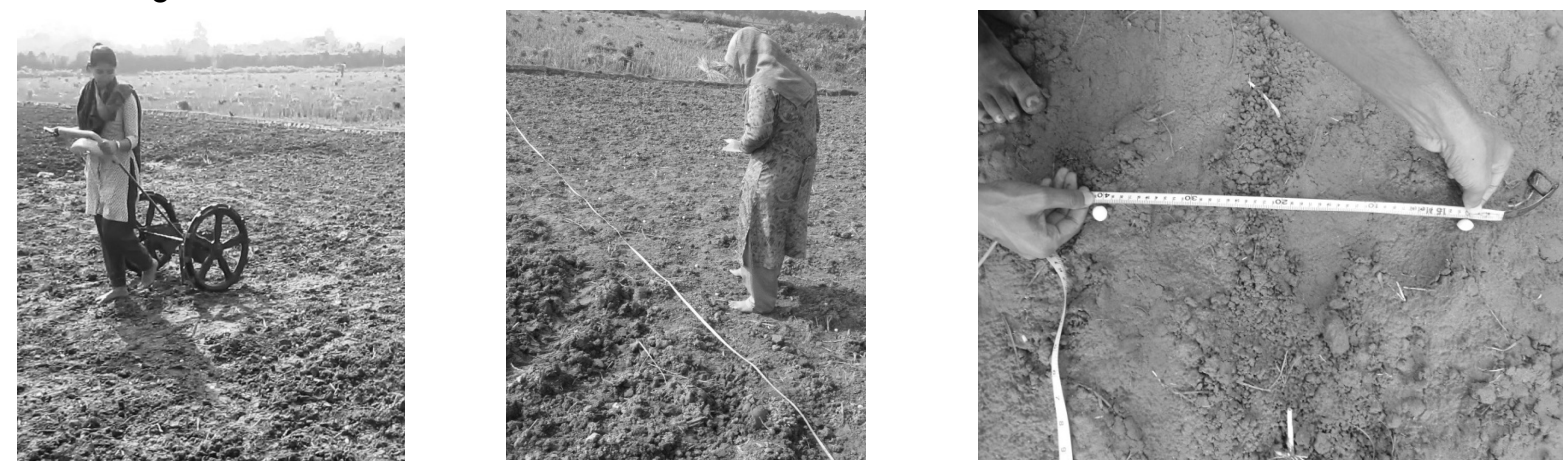

Fig. 3. Photographic views of operation of applicator and measurement of distance between GU to GU 


\section{Field trial of machine in puddle field}

The test of the applicator was conducted in the puddle field to collect data for determining the overall performance of the machine; operating speed, field capacity, field efficiency and cost per unit area of the machine. Time of trail was recorded with a stopwatch. The length and the width of the land were measured by a measuring tape to calculate the area. The effective field capacity of the machine was determined dividing the total area by total time required and expressed the result in ha/hr.

\section{Traveling speed of the machine}

This is a manually operated applicator. Therefore the speed of the machine was varied with the walking speed of the operator. The dropping of GU also depends on traveling speed of the machine, field condition and amount of GU in the hopper. The speed of the machine was determined using the following equation:

Speed, $s=\frac{d}{t}$

where, $\mathrm{d}=$ distance traveled in $\mathrm{m}$, and $\mathrm{t}=$ time in sec.

\section{Field capacity of the machine}

Field capacity is defined as the rate of field coverage by the applicator. Theoretical field capacity of the machine was calculated using the following equation (Hunt, 2004);

Theoretical field capacity $\left(\frac{\mathrm{ha}}{\mathrm{hr}}\right)=\frac{\mathrm{SW}}{\mathrm{C}}$

where,

$$
\mathrm{S}=\text { speed in } \mathrm{km} / \mathrm{hr}, \mathrm{W}=\text { width in } \mathrm{m}, \mathrm{C}=\text { constant, } 10
$$

Effective field capacity is the actual rate of field coverage by the machine or implement. Effective field capacity of the machine was calculated using the following equation:

Field capacity $\left(\frac{\mathrm{ha}}{\mathrm{hr}}\right)=\frac{\mathrm{A}}{\mathrm{T}}$

where, $\mathrm{A}=$ total area covered by machine in ha, and $\mathrm{T}=$ total time in $\mathrm{hr}$

\section{Field efficiency}

Field efficiency is the ratio of the effective field capacity to theoretical field capacity. It is also ratio of the theoretical field time to the total time spent in the field. It includes the effects of time lost in the field and failure to utilize the full width of the machine. Field efficiency of the machine was calculated using the following equation;

$$
\text { Field efficiency , e }(\%)=\frac{\text { Effective Field capacity }\left(\frac{\mathrm{ha}}{\mathrm{hr}}\right)}{\text { Theoretica I Field capacity }\left(\frac{\mathrm{ha}}{\mathrm{hr}}\right)} \times 100
$$

\section{Application rate}

Application rate of the machine is the amount of granular urea dropped in the per unit area of the field. This parameter was determined by measuring the weight of GU in hopper of the machine before and after the application and area covered during the operation. The weight of GU in hopper was measured by electric balance. Length and width of the field were measured by a tape for calculating area. The application rate was determined by the following equation.

$$
\text { Application Rate }=\frac{\mathrm{W} 1-\mathrm{W} 2}{\mathrm{~A}}
$$

where, $W_{1}=$ Weight of granular urea into two hoppers before operation in $\mathrm{kg}, W_{2}=$ Weight of granular urea remain into the two hoppers after operation in $\mathrm{kg}$, and $A=$ Area covered in ha . 


\section{Determination of cost of the machine}

When a new technology is introduced in the field, farmers are interested to know whether the machine will be profitable to them or not. Cost analysis is very important for a new technology. Operational cost of the machine is the sum of fixed cost and variable cost of the machine. The total cost of the machine was determined by knowing the cost of the materials used to fabricate the applicator and fabricating cost of the machine. The operational cost (Tk/ha) and the annual cost $(\mathrm{Tk} / \mathrm{yr}))$ were calculated by assuming depreciation cost, interest on investment, tax, insurance, shelter, repair maintenance cost, and annual use of the machine etc. Annual cost of the GUA was determined using the following equation (Hunt, 2004);

Annual cost $(\mathrm{TK} / \mathrm{yr})=\frac{\mathrm{FC}(\%) P}{100}+\frac{10 \mathrm{~A}}{\mathrm{SWe}}((\mathrm{R} \& \mathrm{M})+\mathrm{L}+\mathrm{O}+\mathrm{F}+\mathrm{T})$

where, $\mathrm{FC}=$ fixed cost in Tk/yr, $\mathrm{P}=$ purchase price in Tk, $\mathrm{A}=$ area covered in ha, $\mathrm{S}=$ forward speed of the machine in $\mathrm{km} / \mathrm{hr}, \mathrm{W}=$ width of the machine in $\mathrm{m}$, e = field efficiency in \%, R\&M = Repair \& Maintenance cost, $3 \%$ of purchase price, O, F, T = oil, fuel \& tractor cost respectively nil, and L= Labor cost in Tk/hr

\section{Comparison of yields for GU placing by different methods}

After studying the performance of pull type two rows granular urea applicator, field experiments were conducted to compare the performance of the existing and the developed GUA. For this experiment, the field was prepared by a power tiller. After tillage operation, irrigation was applied for puddling purpose. Then, seedlings were transplanted in the field. After 25 days of transplantation, granule urea was placed as follows in the rice field at BAU farm in Randomised Complete Block (RCB) design with 3 replications. The treatments were;

$\mathrm{T}_{1}=$ granular urea were applied by hand,

$\mathrm{T}_{2}=$ granular urea were placed using BRRI made push type GUA,

$\mathrm{T}_{3}=$ granular urea were applied using the developed pull type GUA.

The size of each plot was $63 \mathrm{~m} \times 3 \mathrm{~m}$. Total time, lap time, turning time was recorded by a stop watch and area was measured by tape. From this information, field capacity and field efficiency were calculated by the formula describe in above sections. Field capacity, rice yield and economic performance of the granular urea applicator were calculated and compared among different methods.

\section{Descriptive analysis}

Descriptive analysis is a statistical analysis. It was done for almost every data which were measured in the experiment; such as weight of $\mathrm{GU}$, distance between $\mathrm{GU}$, force required, missing rate etc. In descriptive analysis different statistical parameter were measured those are mean, median, mode, range, skewness, kurtosis, standard error, standard deviation, sample variance, minimum, maximum etc.

\section{Results and Discussion}

The weight each of $23 \mathrm{GU}$ was taken by an electric balance and size was measured by a slide calipers. Then descriptive statistics of weight and size were determined, Table 2. It was observed that the mean weight of the GU was $2.83 \mathrm{gm}$ and median and mode were $2.80 \mathrm{gm}$. It is indicated that weight of GU not varied significantly. On the other hand, it was found that the maximum size of $G U$ was $2.28 \mathrm{~cm}$ and the mean size of GU was $2.16 \mathrm{~cm}$ with $0.073 \mathrm{~cm}$ standard deviation. This result indicated that the size of the sample mostly uniform. However, the diameter of cup of metering device was designed as $2.28 \mathrm{~cm}$ to cover the maximum size of the GU.

Table 2. Descriptive statistics of weight \& size of GU

\begin{tabular}{|l|c|c|}
\hline Statistical parameter & Weight, gm & Size, cm \\
\hline Mean & 2.83 & 2.16 \\
\hline Median & 2.80 & 2.17 \\
\hline Mode & 2.80 & 2.23 \\
\hline Standard Deviation & 0.16 & 0.073 \\
\hline Minimum & 2.5 & 2.00 \\
\hline Maximum & 3.2 & 2.28 \\
\hline
\end{tabular}




\section{Missing and over falling percentage of GU}

The missing and over falling (more than one GU) of GU was determined in the laboratory and the descriptive statistics of the results were presented in Table 3 . It is observed that the average missing rates and over falling from left \& right hoppers were $0.73 \%, 0.45 \%, 0.18 \%$ and $0.63 \%$ respectively. The most frequently occurred missing and over falling percentage for both were 0.00 . The median of missing and overfalling percentage were found as 0.00 . However, the kurtoses of missing and over falling rates from both the hoppers are very close to 0.0. It indicates that the distributions of GU drop are uniform. Maximum missing rate and over falling rates from both the hoppers were $3 \%$.

Table 3. Descriptive statistics of missing \& over falling percentage of left and right hoppers

\begin{tabular}{|l|c|c|c|c|}
\hline Statistical parameter & \multicolumn{2}{|c|}{ Missing percentage } & \multicolumn{2}{c|}{ Over falling } \\
\hline Mean & Left hopper & Right hopper & Left hopper & Right hopper \\
\hline Standard Error & 0.73 & 0.45 & 0.18 & 0.63 \\
\hline Median & 0.33 & 0.21 & 0.18 & 0.24 \\
\hline Mode & 0.00 & 0.00 & 0.00 & 0.00 \\
\hline Standard Deviation & 0.00 & 0.00 & 0.00 & 0.00 \\
\hline Sample Variance & 1.11 & 0.69 & 0.60 & 0.81 \\
\hline Kurtosis & 1.22 & 0.47 & 0.36 & 0.65 \\
\hline Skewness & 0.02 & 0.98 & 11.00 & -0.76 \\
\hline Range & 1.19 & 1.32 & 3.32 & 0.85 \\
\hline Minimum & 3.00 & 2.00 & 2.00 & 2.00 \\
\hline Maximum & 0.00 & 0.00 & 0.00 & 0.00 \\
\hline
\end{tabular}

\section{Pulling force \& draft power}

Require pulling force of the granular urea applicator was recorded by video camera in every minute for half an hour operation. The forces were read and performed the descriptive analysis using MS Excel program. The results of descriptive analysis are shown in Table 4.

\section{Table 4. Descriptive statistics of pulling force}

\begin{tabular}{|l|c|}
\hline Statistical parameter & Pulling force, $\mathrm{kg}$ \\
\hline Mean & $\mathbf{9 . 2 8}$ \\
\hline Standard Error & 0.38 \\
\hline Median & 9.5 \\
\hline Mode & 9.5 \\
\hline Standard Deviation & $\mathbf{1 . 6 3}$ \\
\hline Sample Variance & 2.65 \\
\hline Kurtosis & 2.77 \\
\hline Skewness & -1.67 \\
\hline Range & 6 \\
\hline Minimum & $\mathbf{5}$ \\
\hline Maximum & $\mathbf{1 1}$ \\
\hline Confidence Level at (95.0\%) & 0.81 \\
\hline
\end{tabular}

From the above table, it is found that the average pulling force was $9.28 \mathrm{~kg}$. Standard deviation of sample data of pulling force was $1.63 \mathrm{~kg}$ and the value of confidence level $(95 \%)$ is 0.81 . The minimum and maximum pulling force were $5 \mathrm{~kg}$ and $11 \mathrm{~kg}$ respectively. That means, the draft forces were varied between $3.00 \mathrm{~kg}$ and $6.62 \mathrm{~kg}$. The drawbar power was $0.03 \mathrm{~kW}$ for $55.38 \mathrm{~N}$ pulling forces at $1.78 \mathrm{~km} / \mathrm{hr}$ speed. 


\section{Field test}

Distribution patterns and spacing between GU on dry land: A long run was conducted in the dry field to find distance of dropping GU or distribution pattern of granular urea. Distribution pattern means distribution of GU drops with respect to the distance. GU drop with respect to the distance travel from left and right hoppers of the machine are shown in Fig. 4 \& Fig. 5 respectively. It was also observed that the over falling (2 GU at time) was $10 \%$ and $3.3 \%$ for left hopper and right hopper respectively. Overfilling was occurred due to small sizes of 2 granular urea. The average weight of 2 dropping GU was $2.98 \mathrm{gm}$. Other hand, the urea drop missing percentage is $3.3 \%$ for left hopper but there is no missing of urea drop from right hopper. However, overfilling due to small sizes of $\mathrm{GU}$ is not so harmful rather than missing of GU in crop production. Therefore, the performance of GUA is acceptable.

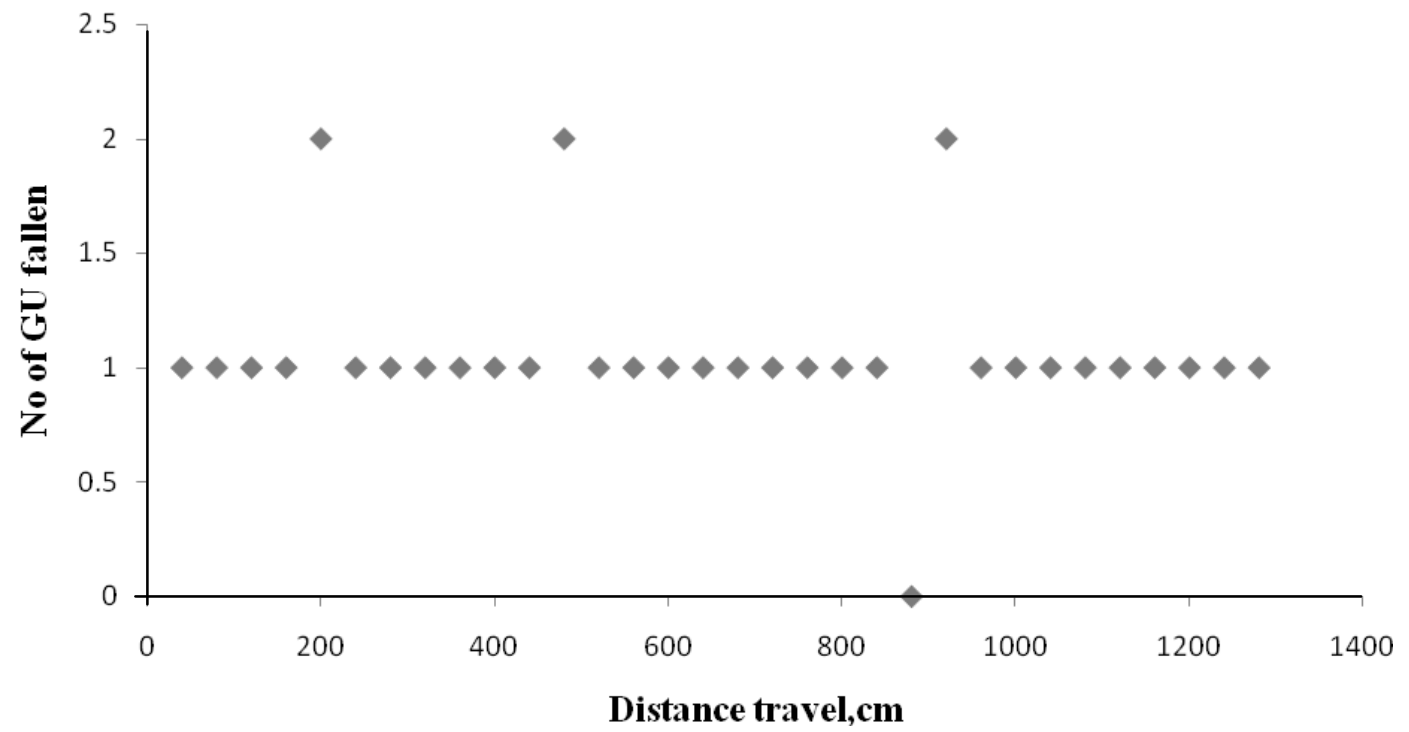

Fig. 4. Distribution pattern of GU drop from left hopper

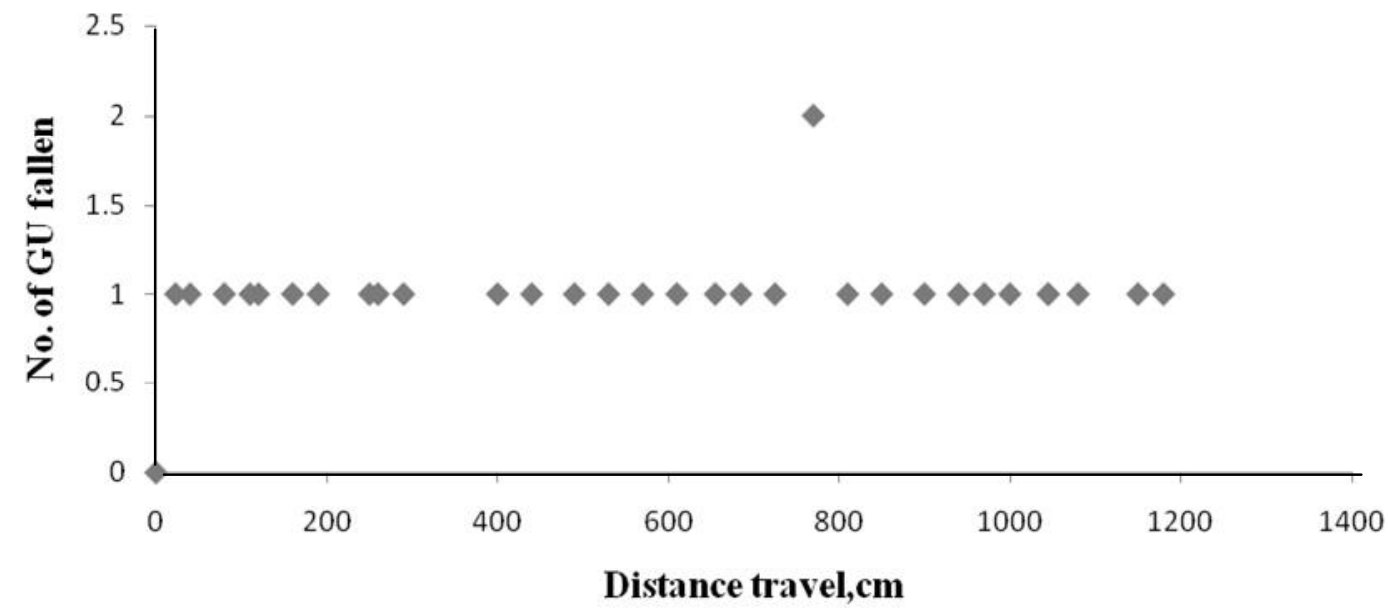

Fig. 5. Distribution pattern of GU drop from right hopper

Machine was operated in a plot of $124 \mathrm{~m}^{2}$ to find the distance between dropped GU, lap time \& turning time. Total number of lap was 13 . Time require to cover a lap, turning time and average distance of drop GU in each lap is presented in Table 5. The average distance between GU to GU on dry land from left hopper \& right hopper were $40.64 \mathrm{~cm} \& 40.89 \mathrm{~cm}$ respectively. The average forwarding speed and time losses for turning in dry land are $9.48 \mathrm{~m} / \mathrm{s}$ and 6.83 see respectively. 
Table 5. Speed, turning time loss \& distance between GU in dry land operation

\begin{tabular}{|c|c|c|c|c|}
\hline Lap no. & $\begin{array}{c}\text { Average time per } \\
\text { lap, m/sec }\end{array}$ & $\begin{array}{c}\text { Total turning } \\
\text { time, sec }\end{array}$ & \multicolumn{2}{|c|}{\begin{tabular}{c} 
Average distance between GU to GU on dry land, cm \\
\cline { 3 - 4 }
\end{tabular}} \\
\cline { 3 - 4 } & 9.35 & 6.50 & 41.29 & 40.20 \\
\hline 1 & 9.52 & 6.00 & 39.00 & 40.50 \\
\hline 2 & 9.44 & 7.40 & 42.28 & 39.78 \\
\hline 3 & 9.48 & 5.80 & 39.50 & 41.20 \\
\hline 4 & 9.55 & 8.00 & 41.80 & 40.10 \\
\hline 5 & 9.26 & 6.00 & 41.20 & 42.20 \\
\hline 6 & 9.28 & 4.90 & 40.50 & 42.00 \\
\hline 7 & 9.36 & 6.00 & 41.50 & 43.00 \\
\hline 8 & 9.38 & 7.20 & 38.90 & 41.00 \\
\hline 9 & 9.60 & 8.10 & 40.00 & 39.60 \\
\hline 10 & 9.55 & 6.80 & 40.80 & 40.10 \\
\hline 11 & 9.85 & 7.60 & 40.50 & 40.60 \\
\hline 12 & 9.69 & 8.50 & 41.00 & 40.89 \\
\hline 13 & 9.48 & 6.83 & 40.64 & \\
\hline Average & & & & \\
\hline
\end{tabular}

Comparison the performance and cost of GU placement in different methods: Granular ureas were placed by developed GUA, BRRI made GUA and manual methods in puddle rice field to compare performances and yield. Field performances of both the machines are presented in Table 6. It is observed that the effective field capacity of developed GUA has increased by $22.22 \%$ compare to that with the BRRI made GUA. It is due to increase of forwarding speed and decreasing of turning time loss compare to those with the BRRI made GUA. The cost of the developed machine is Tk.6000/-.

The costs for GU placement by different methods were calculated. It was found that GU placement per hectare was decreased by $22.16 \%$ for using developed GUA compare to the use of BRRI made GUA. It was decreased by $80.5 \%$ compare to manual placement of GU. On the other hand annual cost (Tk./yr) for using developed GUA was decreased by $5.01 \%$ compare to the use of BARI made GUA. Costs for different application methods of GU placement are shown Fig. 6.

\section{Table 6. Field performance of developed GUA \& BRRI made GUA}

\begin{tabular}{|l|l|c|c|}
\hline Field parameters & unit & Developed pull type GUA & BRRI made push type GUA \\
\hline Average speed in puddle field & $\mathrm{km} / \mathrm{hr}$ & 1.78 & 1.75 \\
\hline Width of the machine & $\mathrm{cm}$ & 80.00 & 80.00 \\
\hline Theoretical field capacity & $\mathrm{ha} / \mathrm{hr}$ & 0.14 & 0.14 \\
\hline Average effective field capacity & $\mathrm{ha} / \mathrm{hr}$ & 0.11 & 0.09 \\
\hline Field efficiency & $\%$ & 77.25 & 64.00 \\
\hline Average turning time loss per lap & $\mathrm{Sec}$ & 7.95 & 9.54 \\
\hline
\end{tabular}

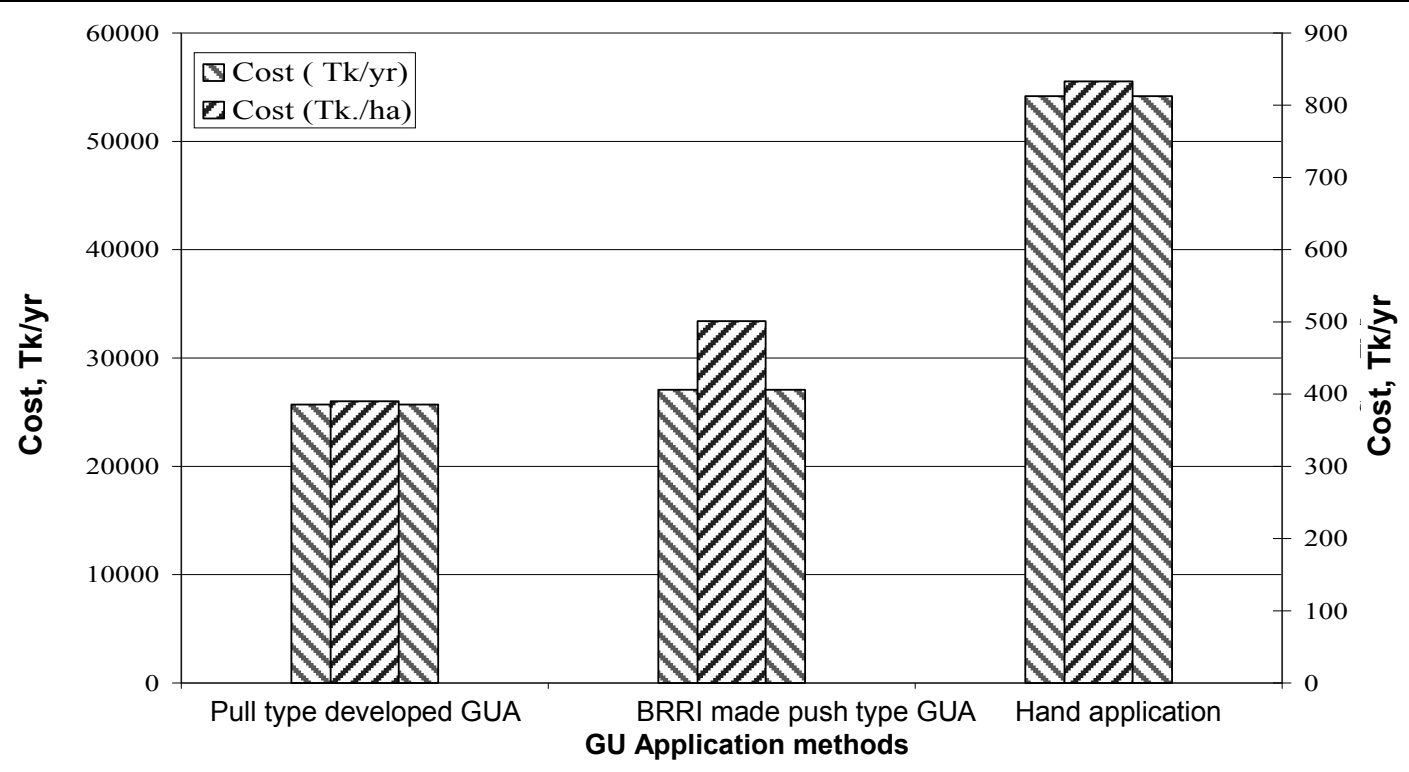

Fig. 6. Costs of GU placement in different application methods 
Grain yields were obtained from different methods. Average grain yield was highest $(5234 \mathrm{~kg} / \mathrm{ha})$ when granular urea were applied by the developed applicator and followed by GU applied by BRRI made push type GUA (5213 kg/ha) and GU applied by manually (5209 kg/ha). However the differences of grain yields were not significantly difference for applying GU by the applicators and manual operation. The influence of different methods of GU application on grain yield \& straw yield has been shown in Table 7 . The highest straw yield $(6787 \mathrm{~kg} / \mathrm{ha})$ was obtained when GUs were placed by manually method then the GU applied by other methods. However the differences of straw yields were also not significantly difference for applying GU by different methods.

Table 7. Effect of GU application methods on rice and straw productions

\begin{tabular}{|l|c|c|}
\hline Urea application methods & Grain yield $\left(\mathrm{kg} \mathrm{ha}^{-1}\right)$ & ${\text { Straw yield }\left(\mathrm{kg} \mathrm{ha}^{-1}\right)}^{6762 \mathrm{a}}$ \\
\hline GU applied by the developed GUA & $5234 \mathrm{a}$ & $6744 \mathrm{a}$ \\
GU applied by BRRI made GUA & $5213 \mathrm{a}$ & $6787 \mathrm{a}$ \\
GU applied manually & $5209 \mathrm{a}$ & 801.80 \\
\hline Level of significance & ${ }^{\star *}$ & 7.45 \\
\hline LSD & 465.00 & 5.62 \\
\hline CV & 5
\end{tabular}

In a column, figures having same letter (s) do not differ significantly, whereas figures bearing different letter (s) differ significantly. ${ }^{* *}=$ Significant at $1 \%$ level of probability

Performance of furrow opener and covering device: The performance of the furrow opener and covering device were observed during the test of the applicator in the puddle field. It was observed that both the units were worked properly. The weight of the whole applicator is only $15 \mathrm{~kg}$ which is easy to carry. The maximum drawber pulling power was $0.03 \mathrm{~kW}$ for $55.38 \mathrm{~N}$ pulling force at $1.78 \mathrm{~km} / \mathrm{hr}$ speed. Therefore, one man or women can pull the machine very easily.

\section{Conclusion}

It is observed that the effective field capacity of developed granular urea applicator is $0.11 \mathrm{ha} / \mathrm{hr}$ at forward speed $1.78 \mathrm{~km} / \mathrm{hr}$ and $78.89 \%$ field efficiency which is better than the existing GUA. The average distance between two dropped granular urea (GU) from the hoppers is $40.64 \mathrm{~cm}$ which is the requirement of granular placement. On the other hand, average missing percentage is only $1.65 \%$ and average over falling ( $2 \mathrm{GU}$ at time) is $6.6 \%$. However, over falling is occurred due to small sizes of $2 \mathrm{GU}$ and average total weight of 2 ureas were $2.88 \mathrm{gm}$. Therefore, it will not be harmful for plant growth \& rice yield. The weight and the puling power of the applicator are $15 \mathrm{~kg}$ and $27 \mathrm{~W}$ respectively. Therefore, one person (man or women) is enough to pull the machine. The operational cost of the applicator is $390 \mathrm{Tk} / \mathrm{ha}$ which is $22.16 \%$ lower than that of BRRI made push type GUA and $53 \%$ lower than the manually placement of GU. Therefore, it may be concluded that pull type two rows granular urea applicator may be introduced in Bangladesh for granular urea application in rice fields.

\section{References}

Kundu, A. and Karim, F. 2012. Design and Development of a Pull Type Two Rows Granular Urea Applicator. Project Report-2012, Department of Farm Power and Machinery, BAU, Mymensingh.

Bhuiyan, N I, Miha, M.A.M. and Ishaque, M. 1998. Research on USG: Findings and Future Research Areas and Recommendations. Paper presented at the national Workshop On urea Super Granule Technology (USG), held at BARC, Dhaka, Bangladesh, 25 June, 1998.

Hunt, D. 2004. Farm Power and Machinery Management. IOWA STATE UNIVERSITY PRESS, AMES, IOWA; pp. 5-72.

IFDC. 2005. International Fertilizer Development Center, Report on urea deep placement as an option for increasing nitrogen use efficiency; IFDC-Asia Division.

IFDC. 2007. International Fertilizer Development Center, Report on fertilizers and agricultural intensification IFDC"s experiences; IFDC-Asia Division

NAP. 2009. National Agricultural Policy report on fertilizer application, Government of the People's Republic of Bangladesh, p-20. 